Die Aufarbeitung des vom Sturm geworfenen und gebrochenen Holzes und dessen Vermarktung, die Bekämpfung der zu befürchtenden Schäden durch Insekten und Pilze und die Wiederaufforstung der umfangreichen Flächen ist den betroffenen Besitzern des Privat- und Körperschaftswaldes, insbesondere den Waldbauern, nicht möglich. Der Deutsche Forstwirtschaftsrat erbittet daher vom Bund und den Ländern die Bereitstellung der notwendigen öffentlichen Mittel.

Maßnahmen der Selbsthilfe, wie Austausch von Arbeitskräften, Maschinen und Geräten sowie Einrichtungen zur gemeinsamen Holzvermarktung, sind in Aussicht genommen.

Auf handelspolitischer Ebene werden Einfuhrbeschränkungen für Holzsorten, die im Inland durch den Windwurf in größerem Maße angefallen sind, beantragt. Auf dem Gebiet der Verkehrswirtschaft werden Ausnahmetarife der Fernverkehrsträger und Begünstigung des Nahverkehrs erwartet. Auf dem Gebiet der Besteuerung wird vom Deutschen Forstwirtschaftsrat Rücksicht auf die schwierige wirtschaftiche Lage, insbesondere des Privatwaldes, erbeten.

Diese Maßnahmen der öffentlichen Hand und der Selbsthilfe benötigt die deutsche Forstwirtschaft, um die Schäden der großen Sturmkatastrophe soweit wie möglich bewältigen zu können. Für viele Waldbesitzer bedeutet die Sturmkalamität ungeachtet aller Maßnahmen eine schwere Existenzgefährdung.

\title{
Verleihung des Wilhelm-Leopold-Pfeil-Preises für das Jahr 1967
}

Der Professor der Forstwirtschaft Dr. G. Hellinga, Wageningen, und der Forstmeister J. F. L. Overbeek, Zwolle, erhalten die beiden für das Jahr 1967 von der Stiftung F.V.S. zu Hamburg zur Verfügung gestellten Wilhelm-Leopold-Pfeil-Preise. Das Preiskuratorium unter Vorsitz von Professor Julius Speer, Bad Godesberg, will mit diesem Beschluß ihre gemeinsamen Verdienste um die Polderaufforstung in Holland auszeichnen.

Der Wilhelm-Leopold-Pfeil-Preis ist der Förderung einer beispielhatten Waldwirtschaft in Europa gewidmet. Jeder der beiden für 1967 zur Verfügung gestellten Preise ist mit 10000 DM dotiert. Außerdem erhalten vier junge Forstleute, ein Spanier, ein Liechtensteiner und zwei Deutsche je ein Stipendium für Studienreisen in Höhe von je 1500 DM.

Die Auszeichnungen werden von der Universität Freiburg im Rahmen der diesjährigen Forstlichen Hochschulwoche Ende Oktober verliehen.

\section{BUCHBESPRECHUNGEN}

Die Waldpflege. Von Hans Leibundgut, o. Professor für Waldbau an der Eidgenössischen Technischen Hochschule in Zürich, mit einer Neubearbeitung der "Auslesedurchforstung als Erziehungsbetrieb höchster Wertleistung "von WALTER SCHÄDELIN. Verlag Paul Haupt, Bern 1966. 19,80 DM.

WaLter SchäDElins Buch „Die Auslesedurchforstung“, 1934, 1935 und 1942 in drei Auflagen kurz hintereinander erschienen, gehört zu jenen Büchern, welche die waldbauliche Entwicklung des vergangenen halben Jahrhunderts offensichtlich stark beeinflußt haben. SCHÄDELiNs Ideen - mehr noch als seine wohldurchdachten Vorschläge im einzelnen - haben den Pflegebetrieb auf eine neue Basis dadurch gestellt, daß die Bestandseingriffe den Lebensphasen 